\title{
A dialéctica na acção dramática do século XVIII
}

\author{
Maria Orquídea Leite de Faria Borges ${ }^{1}$ \\ Escola Superior de \\ Educação de Coimbra
}

O século passado - o século XX - abre, literariamente falando, com a procura interior do Homem que tenta descobrir o mundo descobrindo-se. Estou a pensar no artista surrealista que, a todo o custo e recorrendo aos meios ao seu alcance - como a escrita automática -, pretende atingir a realidade penetrando no mais íntimo de si mesmo, ou seja, no pensamento puro, na Ideia. O microcosmos como via de acesso ao macrocosmos. Já Protágoras (485-480 a. C.) exprimiu este conceito, ao mesmo tempo que dava conta da limitação humana, na máxima: o homem é a medida de todas as coisas. A procura de si conduz à descoberta do cosmos e do Outro porque a humanidade está unida pela sua essência, pelo sopro divino se assim quisermos chamar - essa centelha de luz, de força inteligente. Sócrates já o exprimiu no século V - IV a. C. ao formular o princípio - conhece-te a ti mesmo. Explorando esta imagem desembocamos no chavão que transita do final desse século para o século XXI e que se torna um slogantodos diferentes todos iguais.

Para chegarmos até esta natural aceitação social do Outro, do diferente, houve etapas histórico-políticas que, por sua vez, tiveram na base novas mentalidades gravitando em torno de abordagens filosófico-científicas inovadoras. A revolução francesa com todos os excessos e violências que lhe podemos apontar é um marco na história do homem e, consequentemente, neste caminhar em direcção à igualdade. Podemos dizer que o século

\footnotetext{
1 Bacharel e licenciada em Filologia Românica pela Faculdade de Letras da Universidade de Coimbra. Mestre em Literatura Comparada (Literatura Francesa/Literatura Portuguesa), também pela Universidade de Coimbra. Está em fase de conclusão da tese de doutoramento intitulada " $L$ 'Action du Théâtre de la seconde moitié du dix-huitième siècle" na Universidade Nova de Lisboa. Concentra sua pesquisa na história do teatro, em particular o teatro do século XVIII. E-mail: orquidea@esec.pt.
} 
XVIII assume um papel chave na evolução social e do homem enquanto indivíduo. E os princípios da Revolução Francesa não são novos porque já os encontrámos na Grécia Antiga provindo, uma vez mais, de Sócrates. Quando este filósofo muda o campo de especulação e passa do cosmos para a consciência humana (psicológica e moral) focaliza a reflexão na origem e finalidade da sociedade civil. A relação com o outro sobre a qual assenta a sociedade é, para Sócrates, um produto da reflexão que, libertando-nos do nosso egoísmo, nos obriga a concebermo-nos numa relação de reciprocidade Eu/Outro. Esta dialéctica apela ao exame de consciência com a razão como censor e é não mais do que a regra da justiça social, a base da igualdade ou da fraternidade à luz da razão moral.

Esta mesma natureza dialogante vamos encontrá-la no século das luzes em que a tradição se mantém em diálogo permanente com a inovação. É a velha classe, a nobreza, que, embora perdendo peso económico e político, continua a impor-se como modelo cultural e social. São os países que desenvolvem já uma espécie de intercâmbio e recebem outros modelos culturais e de pensamento, ao mesmo tempo que também exportam, e que põem as diversas formas em diálogo, deixando-se permeabilizar pelo Outro. É, em síntese, o diálogo que antecede e que se segue à aceitação do diferente. E podemos dizer que a grande diferença veio exactamente do outro lado do oceano. O velho continente que, embora considerando-se civilizado face ao recémdescoberto, se deixa "corromper" pela novidade trazida pelas descobertas e permite-se pensar outros modelos sociais e humanos. Como consequência temos o acesso à troca de ideias e a toda uma procura de argumentação de cariz religioso, étnico e político que vai, por si, enriquecer o pensamento.

Trata-se do século em que a razão se impõe, por vezes, dir-se-ia que com a mesma impertinência com que, no classicismo, o fazia o conformista e inquestionável espírito divino. Vendo o século XVIII como um espaço sócio-histórico 
ondulante, em que a tradição é filtrada por uma nova ideologia e em que a sociedade recebe os fluxos de pensamento vindos das novas descobertas e dos novos continentes, somos obrigados a encará-lo como um espaço dialéctico. Queremos com isto dizer que este espaço-tempo dialoga com todos os cronótopos - com o clássico (Antiguidade Clássica e Neo-classicismo), ao tentar racionalizar os seus modelos; com o século XIX que filia o seu pensamento em escolas literárias; com o século XX que chega ao ponto de hastear como conquistas suas os modelos literários e didácticos do século XVIII. Estamos a pensar, neste momento, na presença do leitor na estrutura do romance que, ao participar activamente no desenrolar da acção e ao assumir esse seu papel de forma inequívoca, altera completamente o modo de pensar a criação literária. $\mathrm{Na}$ sua forma de pensar ou construção mental, o escritor, até ao século XVII, confundia-se com o leitor porque os dois se situavam na mesma classe social, não sentindo, assim, necessidade de entrar em diálogo com o seu leitor e perdendo-se, por conseguinte, a componente da recepção neste processo. Assim sendo, a função social do escritor ficava restringida. Ao mesmo tempo em que se atribui ao leitor um papel activo estamos a pensar em Jacques le fataliste et son maître de Diderot - o diálogo passa a marcar presença neste género literário, aproximando-o da forma dramática. Esbatem-se, assim, as fronteiras entre os géneros, entrando a literatura num processo de uniformização.

O teatro que se divide entre dois papéis - o de espelhar a sociedade e o de actuar sobre a sociedade - reflecte bem esse processo que passa, naturalmente, por uma oscilação entre vários modelos. Modelos literários, no que diz respeito à forma, à estrutura, à acção, e também modelos humanos e sociais, no que diz respeito às personagens e situações criadas. Interessam-nos particularmente os modelos literários, muito embora saibamos que se trata de um todo. E aqui importa referir que a retenção da designação de drama, enquanto género dramático abrangente, 
passou por várias outras designações que têm sido consideradas como meros nomes classificativos. De facto, o nosso princípio é o de que, ao contrário do que tem sido afirmado, não foi o nome que oscilou mas sim o conteúdo. Isto é, a passagem do rigor clássico, no que diz respeito à forma, ao conteúdo, ao público, à classificação, e até ao local de apresentação, para uma produção dramática uniformizada, no que respeita as mesmas vertentes, não se processou de forma rápida e inequívoca. Houve aqui um processo - com duração temporal - em que se fizeram sentir influências estrangeiras, nomeadamente inglesas, e em que se saltou de modelo para modelo, usando da liberdade que promove a revolução francesa. Assim, passou a chamar-se a tudo drama, desde que se movimentasse entre o sério e o cómico, ou seja desde que fosse condimentado com estes dois ingredientes. Fezse crer que se tratava da procura de uma designação para o novo género que se criava.

O facto é que quando se quer fazer crer que, antes de se fixar o nome de drama, se passa por designações como a de comédie larmoyante ou a de tragédie bourgeoise, está a esquecer-se a realidade do século XVIII. Ou seja, está a esquecer-se o factor movimento, agitação, ebulição, como queiramos chamar-lhe, que faz dela um cronótopo carismático, de cruzamento de mentalidades, ideologias, de ideias e modos de estar contrastantes a priori. No fundo, estamos a falar da fronteira entre o mundo clássico, rígido, e o mundo moderno, eclético, aberto à diferença vinda do exterior. Na realidade, aquilo que se pensa ser a procura de uma designação para o novo género, é não mais do que a passagem por vários géneros, entre os quais, modelos importados, nomeadamente de Inglaterra, de Itália, de Espanha. Procura-se um género que eduque segundo determinados parâmetros e que vai aparecer como consequência de teorização feita nesse sentido.

O suporte teórico, imprescindível à definição de objectivos da produção dramática, deve sustentar a nova ideologia, os novos valores sociais, os objectivos políticos. A 
necessidade de teorização deve-se, exactamente, à profusão de modelos que dificultam a criação de um género específico.

Tem-se vindo a classificar de drama os géneros mais variados. O exemplo, talvez mais esclarecedor, é o da classificação das peças de Beaumarchais e que são: Eugénie, Les Deux Amis on Le Négociant de Lyon e, por último, a trilogia composta por: Le Barbier de Séville, Le Mariage de Figaro e La Mère Coupable. Em nosso entender, e contrariando a classificação habitual de drama para estas peças, só existe aqui um drama que é a segunda peça, Les Deux Amis ou Le Négociant de Lyon. Na primeira temos uma comédie larmoyante e na trilogia temos duas comédias e uma tragédie bourgeoise na última peça.

Perguntar-se-á porque é que se vê um drama em Les Deux Amis ou Le Négociant de Lyon. A resposta é que é a única peça que educa pela apresentação de um modelo de moral e de carácter irrepreensíveis. Ao contrário da primeira peça, Eugénie pretende educar pela exposição dos erros e das suas consequências nefastas. Por outro lado, em Les Deux Amis ou Le Négociant de Lyon encontramos linearidade numa acção simples. O que não acontece, por exemplo, em La Mère coupable que apresenta uma duplicidade de acção - uma acção trágica interior e uma acção cómica exterior que se aliam num mesmo objectivo.

Poderíamos ainda falar nas personagens - de condição social nobre no primeiro círculo, como convém a uma acção trágica, e de baixa condição quando se trata de fazer intriga (acção da comédia). Isto no que diz respeito ainda à última peça da trilogia porque, se passarmos para a primeira peça de Beaumarchais, Eugénie, vemos que a personagem de intriga passa a ser a tia de Eugénie cuja fraqueza de carácter a torna apta aos jogos de intriga abortados pela virtude da personagem principal, Eugénie, e pela nobreza de carácter do irmão e do pai. Podemos dizer que a tia faz o papel do néscio no melodrama do século XIX. A inocência da jovem vítima consegue transformar a personagem do mal, o conde de Clarendon, que acaba por reparar 
o seu erro e metamorfosear-se em fonte do bem. Assim, temos personagens nobres, de carácter e de condição social, próprias da tragédia, ao lado de personagens de intriga, próprias da comédia. Estas personagens distinguem-se pelo carácter e não pela condição social. Não esqueçamos que um dos objectivos da comédie larmoyante é exactamente a denúncia dos costumes imorais das classes altas da sociedade cujos abusos recaem sobre as mulheres. A estas cabe a correcção dos erros sociais e a eliminação do mal através da virtude. No final, o mal transformado em bem torna-se uma fonte de felicidade. A atmosfera destas peças é de uma grande sentimentalidade, já que a mulher, em torno da qual a acção se desenvolve, é considerada um ser propenso à sensibilidade exacerbada. Aliás, esta nota aparece no adjectivo de designação do género - larmoyante.

A classificação dentro da comédia justifica-se pelo aparecimento da intriga. É de referir que estamos a usar o termo intriga com o sentido de situação confusa, com os quiproquós e os imprevistos próprios da comédia. Neste sentido, ela é aliada do jogo, da pantomima, melhor dizendo, do aspecto lúdico, artificial, do teatro. Tendo em conta a classificação esperar-se-ia, talvez, a introdução do cómico, o que não se verifica. $\mathrm{O}$ assunto é sério e é tratado como tal, o que não quer dizer que não haja notas de inverosimilhança.

É o século da teatromania - toda a gente vai ao teatro e quer estar no palco - aparecem os quadros vivos em que o próprio rei também quer participar. Os enciclopedistas vêem na expressão dramática um bom instrumento de educação e de passagem dos novos valores sociais e humanos. O teatro torna-se o veiculador da nova mentalidade, da nova moral, da moral da nova classe. Há que juntar em cena várias classes sociais - cada uma com os seus valores e costumes o que não é tarefa fácil se pensarmos que até aqui as águas estavam separadas e não se vislumbrava qualquer possibilidade de junção porque eram mundos antagónicos e que se chocavam. Recorde-se que a 
tragédia clássica se destinava à nobreza e o assunto era retirado da mitologia ou da História Antiga. Também o local de representação era distinto do da comédia que, por sua vez, tinha como público-alvo o povo e punha em cena o quotidiano desta classe social com a sua maneira de falar permissiva e picante em que o erótico desempenhava o seu papel.

O século XVIII tem em vista uma sociedade mais igualitária e o gosto desmedido pelo teatro faz com que as fronteiras tendam a desaparecer. Por outro lado, os costumes da classe nobre apelam ao jogo erótico e picante. A nobreza de carácter, o modelo humano apresentado pela tragédia clássica quase não faz sentido numa sociedade à procura de novos princípios e que, entretanto, vai valorizando a intriga que mantém a corte em constante ebulição. O público quer novos conteúdos, mais próximos no tempo e no espaço, e os mentores da revolução francesa não deixam de aproveitar esta oportunidade para the fazer chegar a sua mensagem. Acrescente-se a esta mixage as novas regras sociais e morais impostas por uma classe que aparece trazendo consigo necessidades próprias de uma situação intermédia mas com aspirações socio-políticas. Esta classe burguesa pouco culta reclama modelos que lhe sejam próximos e interessantes. Já que é detentora do dinheiro o teatro deve servir as suas aspirações e apresentá-la socialmente como sendo o novo modelo. Estamos a pensar no drama Le philosophe sans le savoir, de Sedaine, em que se apresenta o comerciante como o modelo de integridade, o verdadeiro nobre nos princípios e na força de carácter. Já falámos de vários géneros dramáticos ou, se tivermos em conta a divisão clássica, sub-géneros como a tragédie bourgeoise, a comédie larmoyante.

Vamos falar agora duma comédia de carácter que apresenta fortes traços da pastoral e da comedia ou comedia nueva, de origem espanhola, mais precisamente de Lope de Vega. Trata-se duma mistura de ingredientes presentes em La partie de chasse de Henri IV, de Collé, escrita em 1774 mas representada em sociedade 
desde 1762. Valoriza-se a tal ponto a figura de Henri IV, o bom rei Henri como lhe chamavam, que Louis XV censura a peça, receoso da comparação. Sendo a personagem principal o próprio rei, todas as outras personagens são súbditos, sejam elas camponeses ou nobres. A inversão do estatuto social faz-se pelo anonimato em que o monarca se encontra e a que ele se vota por brincadeira e um misto de curiosidade. À medida que vai aprofundando o conhecimento das pessoas que o rodeiam, uma família de camponeses, simples e honestos, o seio da verdadeira nobreza, acaba por se entusiasmar e até apaixonar-se por esta viagem de descoberta da verdadeira natureza humana. Os estatutos sociais mostram-se ilusórios pois a corte - frequentada por nobres, na sua maioria desprovidos de princípios e de valores - é exposta como um antro de falsidade. Esta curta peça de três actos faz a sua abertura com as intrigas cortesãs no meio das quais o espectador é lançado vivendo no primeiro acto o mal-estar provocado por um ambiente de falsidade e de mentira. Esta crítica é feita mais adiante pela boca do camponês, no acto II, cena 11, com a crueza ditada pela simplicidade:

Michau

Queu chien de conte ! ça vit à la cour, et ça ne ment jamais! Eh ! C'est mentir, ça.

A manutenção da farsa (sem qualquer intenção negativa) fá-lo descobrir o quão amado é ao mesmo tempo que pode ouvir (em simultâneo com o espectador) a enumeração das qualidades que lhe são atribuídas. Um rei justo tal como o mostra Lucas exprimindo-se na sua linguagem rural:

Paris, mamselle; à celle fin de demander justice a not'bon roi, qui ne la refuse pas pûs aux petits, qu'aux grands.

Com uma ironia inofensiva o rei apodera-se desta linguagem sem artifícios e, talvez por isso sem maldade, em que as palavras não têm outro valor ou outro sentido senão o que lhes 
é próprio. A pureza destas pessoas do campo transmite uma alegria quase infantil e contagiante. É assim que vemos, ou ouvimos, Henri IV falar como um camponês usando de ironia num jogo de palavras já que, referindo-se à bela Catau, utiliza o adjectivo joli:

mais oui; j'aime tout ce qui est joli, moi, j’,aimé tout ce qui est joli.

Através da linguagem obtemos o cómico de situação que vai beneficiar também do desconhecimento da verdadeira identidade do rei. É assim que vemos Catau, a linda jovem, desdenhar da vontade real:

Je le veux, je le veux... comme il dit ça ce monsieu ! Je le veux! Et le roi dit ben nous voulons. Oh! Sachez qu'on ne fait vouloir à mon pere que ce qu'il veut, lui.

Do mesmo modo, o guarda caça (ou guarda florestal) dá ordens ao monarca que obedece numa atitude de humildade e que retribui a naturalidade e pureza de sentimentos quando o dono da casa o manda dormir no sótão:

Oh! J'vous coucherons dans un lit qui est dans not'gregnier en haut, (...)

(...). Je vous aurion bian baillé le lit de not'fils s'il n'étoit pas revenu; mais dame, je voulons que not'enfant soit bien couché par perference.

Responde toujours gaiement et avec bonté, como se pode ler na didascália:

cela est trop juste. Pardieu, je serais fâché de le déranger, et vous avez raison, cela est d'un bon pere.

$\mathrm{Ou}$ ainda de forma mais rude sem deixar lugar para dúvidas sobre quem manda ali, que vontade prevalece: 
Michau, arrachant l'autre chaise.

non, monsieu ; ça ne se passera pas comme ça, vous dit-on.

Tal como as ordens é também o guarda caça quem dá as permissões, depois de passadas as provas. Só autoriza que o rei o trate por "tu" depois de comprovar a sua honestidade observando o seu comportamento no meio da sua família. O tratamento por "tu" foi considerado abusivo, num primeiro momento:

Henri.

Tu me parais un bon compagnon ; et je serai charmé

De lier connaissance avec toi.

Michau, froçant le sourcil.

Tu me parais !... avec toi !... eh mais v's êtes Familier, monsieur le mince officier du roi !

Eh-mais, j'vous valons bian, peut-être ! Morgué, ne M'tutayais pas, j'naimons pas ça."

E continua numa tentativa de explicar retorquindo aos pedido de desculpa do rei:

“(...); c' nest point que je soyons fiars ; mais c'est que n'admettons point de familiarité avec qui que ce soit, que paravant je n' sachions s'il le mérite, voyais-vous.

Reforça esta ideia da conquista do tratamento por "tu":

"Oh! Quand je vous connaittrons, ça s'ra différent." (Acto II, cena 11)

A autorização não se faz esperar, mas Michau faz questão de ser ele a conduzir este processo de intimidade:

Vous êtes mon homme. Suivais-moi : je voyons que nous nous tutayerons bien-tôt à table. J'allons vous faire boire du vin que je faisons ici ; il est excellent, quand ce serait pour la bouche du roi. Laissais faire, nous allons nous en taper.

Perante uma atitude tão rigorosa nos princípios de hospitalidade e tão firme na marcação das fronteiras, é o monarca quem pede até para ser ouvido, num jogo muito irónico:

Michau.

Queuque vous marmotais là tout bas? Allons, allons, qu'on me suive. 
Henri, d'un ton de badinage.

je le veux bien ; mais auparavant voudriez-vous

bien m'entendre? Me ferez-vous cette grace-là?

Este quiproquó é levado às últimas consequências sob a aquiescência do bom Henri que permite que o tratem como um estrangeiro curioso ao ponto de ser inconveniente e que é preciso pôr no seu lugar. Este papel é desempenhado pelo pai, Michau, o guarda caça, mas também por Catau, a jovem camponesa.

Michau.

Oh ça, c'est eune autre histoire, que Richard ne se soucient peut'êt pas de vous dire, voyais-vous.

Henri

En ce cas là, j’ai tort ; pardonnez mon indiscrétion.

Mais adiante, no final do $2^{\circ}$ acto, a jovem reage à tentativa de ajudar:

Henri, tenant quelques assiettes.

tenez, ma chere Catau, où faut-il porter ce que je tiens là.

Catau.

Eh! Laissez-moi faire. Pardi, mon cher monsieu, vous avais toujours les mains fourrées par-tout.

O rei tira prazer deste tratamento de igual para igual, deste momento em que, despido e sem máscaras, se permite embarcar numa viagem pelo interior da natureza humana, só possível de ser proporcionada pelo povo do campo:

Henri à part, tandis qu'ils causent tous ensemble. quel plaisir! Je vais donc avoir encore une fois la satisfaction d'être traité comme un homme ordinaire..., de voir la nature humaine sans déguisement ! Cela est charmant! Ils ne prenent seulement pas garde à moi.

O próprio narrador/autor despoja o rei da sua condição social de modo a que fique apenas o homem e a sua natureza exposta à avaliação pública.

Quando, no final da peça, é revestido de realeza, não pode deixar de haver uma exclamação de admiração e sairá certamente 
reforçado no amor dos seus súbditos, para além de, mais uma vez, ter oportunidade de fazer justiça e de restabelecer a verdade solidificando as suas convicções.

O facto é que o perfil do rei se vai desenhando com o decorrer da acção que acaba por pôr em evidência a sua natureza simples, honesta, justa e humilde. Atributos mais facilmente encontráveis no meio rural onde o vemos num à vontade cheio de graça, longe das intrigas da corte. A intimidade para que foi convidado tão simplesmente despojou-o de todo e qualquer artifício e deu lugar ao homem em comunhão com outros homens num ambiente familiar. $\mathrm{O}$ anonimato permitia-lhe tudo mas a sua essência falou naturalmente numa resposta espontânea e graciosa realçando a verdadeira nobreza. Quando os elementos da comitiva chegam, trazem consigo a intriga, o artifício, e quebram o encantamento a que tínhamos estado presos na companhia da boa gente do campo e do bom rei Henri.

Trata-se duma peça sem unidade de espaço - o primeiro acto decorre no palácio de Fontainebleau, na galeria dos reformados; o segundo acto situa-se em espaço exterior, a entrada da floresta de Senart, do lado de Lieursain; e o terceiro acto volta a colocar-nos em interior, na casa do moleiro que é também o guarda caça do rei. Obedece à regra clássica da unidade de tempo. Mas quanto à acção, podemos dizer que não há obediência à lei da unidade visto que tem duas acções paralelas - uma acção amorosa que se prende de modo aparentemente frágil com a acção política. Curiosamente os quiproquós da intriga, enquanto acção da comédia, encontramo-los nos dois campos e a clarificação dum conduz-nos à verdade do outro. $\mathrm{O}$ amor é o motor da acção, é a força que a impulsiona em direcção à verdade - referimo-nos ao impulso amoroso mas também ao amor que une a humanidade, o amor ao próximo, base da igualdade e da fraternidade. A figura do rei Henri IV remete-nos para uma época histórica - a da restauração da unidade religiosa como base da unidade nacional, fraccionada pelos papas Clément VII e Paul 
IIII. Com determinação e espírito de humildade (lembremos o episódio de ter esperado descalço pela absolvição), e acompanhado pelo honesto Sully, Henrique de Navarra, agora Henrique IV, consegue restaurar a autoridade real numa França transformada em palco de lutas entre protestantes e católicos. No texto dramático, pela boca do camponês, temos uma referência a este cenário, mais concretamente à Liga dos católicos, facção fanática (acto II, cena 8):

\footnotetext{
Le Paysan.

Au contraire, et grand merci, mes bons seigneurs.

Suivais-moi. Dame, si je vous ont pris pour

Des voleurs, c'est que ste forêt-ci en fourmille;

Car depis nos guerres civiles, biaucoup de ligueux

Avont pris ste profession-là.
}

A História recente como pano de fundo - estamos no fim do século XVI, princípio do XVII - e a preocupação pela unidade nacional que vamos encontrar mais tarde nos românticos. A favor desta escola e avant la lettre temos também o gosto pela cultura popular aqui tão bem representada pela linguagem que chega a ser adoptada pelo próprio rei. A natureza e o natural têm aqui papéis de destaque. Por outro lado, temos a curiosidade e o interesse pelo conhecimento da natureza humana pela qual Henri IV se apaixona. O facto é que se diria que esta peça consegue movimentar-se entre o classicismo (não perde muito de vista as regras clássicas), a natureza (também a humana) é fonte de prazer, de serenidade e o romantismo (consegue uma enorme abertura projectando-se para a frente utilizando a razão na compreensão histórica dos acontecimentos). Fá-lo tão naturalmente quanto o meio em que somos postos e por isso não precisa de recursos (como o da figura do criado). Talvez seja a atracção dos opostos socialmente.

Este mesmo tema da restauração, desta vez da independência portuguesa, será tratado na comédia histórica Pinto ou La Journée d'une conspiration, de Lemercier, escrita em 1798 e representada em 1800. Desta vez a restauração de que se fala é a 
de Portugal, em 1640. O mesmo tema é tratado por Almeida Garrett na peça D. Filipa de Vilhena ${ }^{2}$ que o próprio autor classifica de comédia histórica (GARRET, s.d., p. 179), muito embora Teófilo Braga, na sua nota introdutória, a classifique de "drama histórico" (Ibid., p. VII). Muito embora a nossa classificação seja de drama entendemos que se tratava, neste momento, duma oposição à classificação de tragédia, na linha de Charles Batteux, contestada por Dupuy, segundo a qual un drame, où le vice est puni et la vertu recompensée, ne peut être une tragédie (MANTION in BATTEAUX, 1989, p. 67).

A data de 1640 foi não só importante para Portugal como para o teatro europeu, uma vez que a progressão da acção trágica - o mesmo é dizer, séria, nobre - pôs de lado a obrigatoriedade do fim funesto. Como explica Georges Forestier, a partir daqui, apresentam-se duas vias possíveis à dramaturgia trágica:

Si l'on veut faire le point sur la situation de la tragédie vers 1640, quand Corneille après le Cid lance la série de ses tragédies romaines, on peut dire que la tragédie est devenue non plus le récit d'une illustre infortune, mais la mise en scène d'une activité hérö̈que face à un conflit politico-amoureux et sous la menace d'un péril de mort : désormais l'issue funeste n'est plus une nécessité. (FORESTIER in CORVIN, 1991, p. 838)

Segundo Charles Batteux, dos quatro mundos pertencentes à natureza, objecto de imitação ou de representação por parte do artista criador, encontramo-nos perante o mundo histórico:

La nature, c'est-à-dire tout ce qui est, ou que nous concevons

aisément comme possible, voilà le prototype ou le modele des arts.

Pour expliquer ceci nettement, on peut distinguer, en quelque sorte, quatre mondes:le monde existant, c'est l'univers actuel,

\footnotetext{
${ }^{2}$ Representada, a primeira vez, no Teatro do Salitre, pelos alunos do Conservatório Real de Lisboa, em trinta de Maio de MDCCCXL, segundo nota da edição a seguir mencionada.
} 
physique, moral, civil, dont nous faisons partie; le monde historique,

qui est peuplé de grands noms, et rempli de faits célebres;le monde

fabuleux, qui est rempli de dieux et de héros imaginaires; enfin le

monde ideal ou possible, où tous les êtres existent dans les généralités

seulement,et d'où l'imagination peut tirer des individus qu'elle characterise par tous les traits d'existence et de propriété (MANTION in BAT'TEUX, Op. cit., p. 86)

O mesmo facto histórico representado de formas diferentes (os títulos são reveladores) porque o olhar seleccionou episódios distintos: o dramaturgo francês escolheu um episódio cómico, sobejamente conhecido e comentado nacionalmente, muito embora se trate dum pormenor; o homem do teatro português, sem preconceito de género, escolhe uma figura feminina que opta pelo amor à pátria em detrimento do amor maternal e arma seus filhos cavaleiros, num acto que, até aí, os homens reservavam para si: A condessa de Atonguia, D. Filipa de Vilhena, armando seus dois filhos para a revolução (GARRET, s.d., p. 179).

O dramaturgo francês fala-nos dum assunto sério como é a História nacional portuguesa num género reputado como menos sério como é a comédia. É neste contexto que vamos abordar a figura do criado, do aio, do confidente ou do secretário - quer dizer alguém que serve uma pessoa que lhe é superior socialmente. Trata-se, por assim dizer, duma personagem nova ou, no mínimo, revestida duma importância inusitada porque até este século ou esteve ausente ou se contentou com um papel figurativo ou muito secundário. O vassalo, já que se trata do secretário Pinto é o condutor da intriga e da acção, à maneira do Figaro de Beaumarchais. A própria duquesa de Bragança o investe de autoridade ao mesmo tempo que nos fala do marido, o duque de Bragança, como sendo uma pessoa menos determinada porque pouco ambiciosa. Aos olhos do espectador ou do leitor, o duque - que será D. João IV - aparece com os princípios mais elevados como se pode ver na cena VI do $1^{\circ}$ acto: 
Le Duc:

S'il faut les défendre [les portugais] en soldat, je suis prêt ; mais me jeter à la tête d'un part qui me couronne, c'est mettre mon ambition particulière à la place du bien de tous.

La Duchesse :

Et si à votre refus le Portugal s'élève en Republique, pour qui vous déclarerez-vous, entre le Roi d'Espagne et ce Gouvernement ?

Le Duc :

Pour ma patrie.

La Duchesse :

Et s'il se choisit un autre Prince?

Le Duc :

Pour ma patrie.

La Duchesse :

Prouvez donc que vous la voulez défendre en cessant de contrarier nos inutiles projets... Arrivez, Pinto, achevez de décider votre maître.

Segue-se um diálogo entre o Duque de Bragança e o seu secretário, uma tentativa de persuasão que é quase um jogo de forças:

Pinto, brusquement:

Morbleu! Monseigneur, si nous succombons, laisseznous

Pendre ; mais si nous l'emportons...

Le Duc, irrité :

Qu'oserez-vous?

Pinto :

Vous proclamer en dépit de vous-même.

Finalmente, deixa-se convencer:

Le Duc:

Vous êtes menacés?... Il suffit ; je n'examine plus rien. Celui-là est ingrat et lâche qui délibère et balance quand ses amis sont en danger. Comptez sur moi.

O que o duque faz em nome da solidariedade para Pinto tem apenas o valor da vitória e a exclamação sai-lhe como um grito de guerra:

Pinto :

C'est assez, Moseigneur. Il est à nous. 
A inversão de papéis ou de peso social manifesta-se na expressão verbal do futuro rei D. João IV que pede aos seus inferiores para ser ouvido:

Le Duc:

De... veuillez m'entendre... (...)

(Cena 12, acto I)

Também aqui temos a intriga amorosa e a intriga política - até se trata duma conspiração - e Pinto movimenta-se no meio das duas, podemos mesmo dizer que conduz as duas, pondo a primeira ao serviço da segunda. O seu papel é tão importante que é ele quem faz as grandes tiradas à boa maneira clássica.

$\mathrm{O}$ duque de Bragança, esse hesita em deixar a vida aprazível das caçadas e dos prazeres simples no seio da família e da natureza, o sonho da aurea mediocritas que se lhe afigura bem mais interessante do que os riscos, responsabilidades e jogos de intriga que o esperam se aceitar o desafio:

\section{Le Duc:}

Vous extravaguez... ou plutôt, pris par ma facilité dans vos pièges, je perds l'aimable douceur, les délices d'une vie égale, riante et paisible. (Cena VIII, acto I)

Esta oscilação entre o gosto clássico (ou neo-clássico) e o romântico (ou até o realista) - vemos as descrições pormenorizadas nas didascálias referentes à decoração encontramo-la também na pintura deste século dourado. Esta expressão artística revela igualmente este diálogo entre o convencional e a tendência para o realismo que teima em se manifestar.

É um século simbiótico este, talvez por balizar um mundo que se apaga e um outro que se anuncia, em que as pinturas nas quais podemos deleitar o olhar e procurar respostas nos desnudam um gosto pleno de antíteses - dum lado a pompa e a sumptuosidade, do outro a simplicidade essencial da natureza morta; a oposição entre o convencionalismo artificial da paisagem 
e a observação precisa e directa da Natureza, a exactidão e simplicidade com que se transpõe o mundo natural.

O teatro encheu-se de quadros e a procura foi a mesma a procura dum princípio único capaz de abarcar a heterogeneidade do gosto social. Tarefa ambiciosa para um século efervescente e prematura porque faltava cumprir uma primeira missão - a educação... do gosto.

\section{BIBLIOGRAFIA CITADA:}

ARISTOTE. La Poétique. Paris, Seuil, 1980.

BATTEUX, Charles. Les Beaux-Arts réduits à un même principe. Paris, Aux amateurs de livres, 1989.

CORVIN, Michel. Dictionnaire Encyclopédique du Théatre. Paris, Bordas, 1983.

DE ROUGEMONT, Martine. La vie théatrale en France an XVIIIe siècle. Paris, Genève, Champion-Slatkine, 1988.

MANTION, Jean-Rémy. In : BATTEUX, Charles. Les beaux-Arts réduits à un meme principe. Edition critique. Paris, Aux amateurs de livres, 1989.

FRANTZ, Pierre. L'esthétique du tableau dans le théatre du XVIIIe siècle. Paris, PUF, 1998.

GARRETT, Almeida. Alfageme de Santarém - D. Filipa de Vilhena. Edição segundo as primeiras edições revistas pelo autor e com um prefácio de Teófilo Braga. Col. Lusitânia. Porto, Lello e Irmão Editores, s.d.

KREBS, Roland; VALENTIN, Jean-Marie. Théâtre, nation et société en Allemagne au XVIIIe Siècle. Nancy, Presses universitaires de Nancy, 1990. KREBS, Roland. L'idée de "Théâtre National" dans l'Allemagne des Lumières. Bland 28, Otto Harrassowitz, 1985.

LAGRAVE, Henri. Le théatre en 1778, in dix-buitième siècle. Paris, Garnier Frères, 1979.

Résumé: La scène évolue en mouvements circulaires issus de la dialectique intrinsèque entre la tradition et l'innovation. Il s'agit d'un dialogue entre les classes représenté par l'interaction de personnages identifiés socialement. Or, la cohabitation scénique de classes distantes - dans les valeurs, les coutumes, voire dans l'expression - entraîne des problèmes de structuration de l'action dramatique. C'est dans ce contexte qu'entre le personnage du serviteur, du valet de chambre ou du confident, qui sert de lien entre ces mondes, sociaux ou psychologiques, différents.

Mots-clef : Dialogue ; chrono tope ; société ; scène dramatique. 